\title{
Is "See One, Do One, Teach One" Dead? Implications for the Professionalization of Medical Educators in the Twenty-First Century
}

\author{
Tristan Gorrindo $^{1} \cdot$ Eugene V. Beresin ${ }^{2}$
}

Received: 31 August 2015 / Accepted: 7 September 2015 /Published online: 16 October 2015

(C) Academic Psychiatry 2015

It is an incredibly exciting time to be a medical educator in psychiatry. Three forces are creating significant challenges and opportunities for innovation in medical education. First, our fundamental understanding of the brain is changing on almost a daily basis as new discoveries in neuroscience are announced. Concepts such as neurocircuitry and pharmacogenomics, widely unknown in the clinical sphere just a decade ago, are now poised to transform our thinking of the brain and treatment of mental illness. Second, movements towards integrated care and patient-centered medical homes have the potential to dramatically change the way psychiatrists practice medicine. Changes in the structure of the US health care system are going to create new roles of psychiatrists within the provision of care that did not exist until recently. And finally, the arrival of the millennial learner in undergraduate, graduate, and continuing medical education is forcing educators to think beyond their natural tendency to stand behind a podium and lecture. The millennial learner is collaborative, technology driven, and self-directed. Awareness of the needs of this kind of learner, along with a greater understanding of assimilating new and complex material, compels us to incorporate principles of adult learning into our pedagogy. Principles such as flipped classrooms, team-based learning, experiential learning, and use of online platforms are transforming medical education.

Skilled and knowledgeable faculty are key to effectively educating students within the context of these forces of change. Whether for content knowledge or pedagogic

Tristan Gorrindo

tgorrindo@psych.org

1 American Psychiatric Association, Arlington, VA, USA

2 Harvard Medical School, Boston, MA, USA strategy, it is increasingly difficult to pull "good clinicians" off the wards to teach on a topic. If a faculty member uses a traditional "see one, do one, teach one" model, it is possible that the instructor may lack the foundational knowledge and pedagogic skill required by today's learner. That is to say, what we are teaching and how we are teaching may have little resemblance to how we learned in medical school and residency. Hence, we now face an additional challenge: how do we integrate faculty development and the time for clinical and basic science educators to learn new pedagogies, when we are all facing increased service demands and new administrative requirements in our schools, clinics, and hospitals? The importance of true faculty development has never been more critical. Whether it is providing faculty with up-to-date content knowledge, an understanding of new teaching models, or new career paths for those who see education as part of their core identity, the need for a professionalized medical education staff becomes paramount, particularly in the use of new teaching methods that involve technology.

The current issue of Academic Psychiatry describes almost a dozen new ways to engage students using technology. For example, Duffy et al. highlight the use of Prezi to build concept maps and increase student engagement in lectures. Lal and colleagues rethink journal club by creating a transAtlantic book group to facilitate peer-peer learning through the co-exploration of literature. Foster et al. look at the application of deliberate practice to addressing suicide assessment competencies.

To many, the smorgasbord of educational interventions in this issue reads like science fiction. For those not fluent in social media, Web-based learning, and mobile apps, these papers may appear like noise and blinking lights without a clear message. Beyond just the technological terms, there is also a morass of pedagogic jargon-SPOCs, deliberate practice, flipped courses, asynchronous learning, peer-peer 
facilitation, mindmaps, virtual standardized patients- - just to name a few. Each of these terms has a specific definition and (emerging) evidence base that support its strategic use in various aspects of medical education - a synergy of the acceptance of adult learning theory and effective use of digital technology. When these tools are added to tools like lectures, bedside rounds, and chalk talks, educators today have more techniques than ever before.

While it is true that the success of any of these projects is driven by a common foundational commitment to basic educational principles - faculty who know their target audience, can craft specific and achievable learning objectives, assess the best pedagogic intervention, and critically evaluate feedback data- this list is sometimes overwhelming and confusing for those who dabble in medical education. It is also daunting and challenging for the professional medical educators without adequate time and resources.

There is a specific knowledge base required in the application techniques such as SPOCs, mobile learning, and virtual patients. Our faculty need training and retraining when it comes to applying these tools. Whether a boot camp in new content knowledge, access to instructional designers who can help them create engaging online courses, or support from department chairs who can provide salary support and protected time for those choosing a career as an educator, the trend is consistent. Core faculty members cannot simply be part-time individuals who teach one to two hours per month around the edges of their busy clinical practices or research endeavors. That is not to say the part-time army of instructors is not valuable, but they should not be seen in aggregate as a replacement for developing faculty who deeply understand the content, pedagogy, and needs of the modern learner.

As a field, medicine has not been proactive in requiring intensive faculty development and nurturing faculty skills to support new educational methods in the classroom, clinic, or bedside. Increasingly, we see the need for this. How we can arm our core faculty with new skills is not a simple or straightforward process. Most departments are constrained by fiscal hardships and are required to cut budgets. Perhaps a national core of leaders in adult learning theory with technological prowess needs to become more active in national meetings and online activities and be invited to grand rounds presentations. This may not be a problem that is solvable by any one department alone, but its inclusion in modern pedagogy is essential.

A national strategy focused on developing, empowering, and solidifying the core principles and resources to support professional medical educators is needed. As knowledge expands and learners change, so too must the way we think about medical educators in the twenty-first century. This issue of Academic Psychiatry highlights the power of technology in teaching, but without skilled educators standing behind it, the full potential of these new tools will not be realized.

Disclosure On behalf of both authors, the corresponding author states that there is no conflict of interest. The opinions expressed here are those of the authors and should not be presumed to be the official position of the authors' institutions. 